\title{
MENTALIDADE EMPREENDEDORA NO LITORAL NORTE PAULISTA: UMA INVESTIGAÇÃO COM DISCENTES DE ENSINO SUPERIOR
}

Artigo recebido em: 17/06/2014. Artigo aprovado em: 26/06/2015.

\begin{abstract}
Ricardo de Lima Ribeiro - Fatec/São Sebastião e Universidade de Taubaté Elvira Aparecida Simões de Araujo - Universidade de Taubaté ${ }^{2}$ Edson Aparecida de Araujo Querido Oliveira - Universidade de Taubaté ${ }^{3}$
\end{abstract}

Resumo: A existência de uma mentalidade favorável à atividade empreendedora pode ser considerada como elemento relevante para a geração e desenvolvimento de riqueza. Isso porque a literatura acerca do tema aponta que parte significativa dos empreendimentos nascidos no Brasil é gerada por pequenos empreendedores, que se tornam os grandes propulsores da economia e do desenvolvimento da região. Nesta pesquisa, busca identificar o grau da mentalidade empreendedora dos discentes de cursos presenciais de ensino superior concluintes em 2013, do Litoral Norte Paulista. Esta amostra foi considerada em virtude do alto potencial empreendedor, proveniente do nível educacional e da faixa etária. Para alcançar o objetivo desta produção acadêmica, foram mensurados os componentes da mentalidade empreendedora destes discentes. Quanto maior o percentual de afirmativas positivas, maior o grau de mentalidade empreendedora. A abordagem utilizada foi a quantitativa, por meio de uma pesquisa de campo e empregou-se como instrumento de coleta de dados, um questionário adaptado do estudo sobre mentalidade empreendedora do Global Entrepreneurship Monitor (GEM). Os dados foram examinados por meio da estatística descritiva. Os resultados alcançados demonstram que os discentes do Litoral Norte possuem elevada mentalidade empreendedora.

Palavras-chave: Gestão; Planejamento; Empreendedorismo; Mentalidade Empreendedora; Desenvolvimento Regional.

\section{ENTREPRENEURIAL MENTALITY IN THE NORTH COAST OF SÃO PAULO: AN INVESTIGATION WITH HIGHER EDUCATION STUDENTS}

Abstract: The existence of a favorable mentality of individuals to entrepreneurial activity is a precondition to generate and develop new enterprises and businesses which promote economic and social growth. The research responded what is the entrepreneurial mentality degree of higher

\footnotetext{
1 ricaribeiro@uol.com.br, Avenida Siqueira Campos, 587 apto 55 Caraguatatuba S.P.

2 elvira.araujo@unitau.com.br

3 edson@unitau.com.br
}

RIBEIRO, R. L.; ARAUJO, E. A. S.; OLIVEIRA, E. A. A. Q. Mentalidade empreendedora no litoral norte paulista: uma investigação com discentes de ensino superior. Revista de Empreendedorismo e Gestão de Pequenas Empresas, v.4, n.2, 2015 
education students of in classroom courses that graduated in 2013, from the North Coast of São Paulo. This sample was considered because the high potential of the educational level and age group. To resolve this issue, this paper considered the entrepreneurial mentality components of the students. The higher the percentage of positive statements about the entrepreneurial mentality, higher its degree. In order to achieve this purpose, the method used was the quantitative research. The study adopted field research and a questionnaire to collect data, which was adapted from study on entrepreneurial mentality of the Global Entrepreneurship Monitor (GEM). The data were examined with a descriptive statistical analysis. Researching about the entrepreneurial mentality is relevant because the literature demonstrates that significant proportion of Brazilian enterprises is generated by small entrepreneurs, who became great propellant of economy and development in the region. Results show that those students of the North Coast of São Paulo have high enterprising mentality.

Keywords: Management; Planning; Entrepreneurship; Entrepreneurial Mentality; Regional Development.

\section{Introdução}

O desenvolvimento da mentalidade empreendedora em uma sociedade é a alternativa para proporcionar a entrada da maior quantidade de indivíduos no mercado de trabalho, por intermédio de pequenas e médias empresas que geram novos empregos (GUERRA; GRAZZIOTIN, 2010).

Nesse sentido, Melo (2012) enfatiza que a disseminação e a valorização da mentalidade empreendedora são alicerces para o crescimento de uma região. Divulgá-la denota desenvolver um conjunto de traços culturais e ideológicos para aprimorar o hábito, individual ou coletivo, na procura de iniciativas e resultados na administração do empreendimento próprio, na participação e na estruturação da criação de renda e emprego.

A mentalidade empreendedora carrega implicitamente, uma decisão consciente e planejada que se estende em atitudes específicas para a criação de um negócio (CARVAJAL et al., 2013). Dessa forma, a constituição de novos empreendimentos produz postos de trabalho, difunde renda e gera oportunidades para todos os habitantes de uma região.

RIBEIRO, R. L.; ARAUJO, E. A. S.; OLIVEIRA, E. A. A. Q. Mentalidade empreendedora no litoral norte paulista: uma investigação com discentes de ensino superior. Revista de Empreendedorismo e Gestão de Pequenas Empresas, v.4, n.2, 2015 
A propagação de um tipo de desenvolvimento, afiançado no estímulo à mentalidade empreendedora, é o método mais eficaz de exercer impacto sobre a economia e a estrutura de uma comunidade (GRECO et al., 2010). Paralelamente, Emmendoerfer e Fonseca (2005) relembram que o empreendedorismo é um fato de natureza sociocultural, dotado de elementos e atitudes comportamentais, que sofre alterações de um local para o outro, resultante do contexto em que se vive.

Como exemplo, têm-se algumas regiões que convergem seus modelos econômicos. As políticas para a geração de negócios e para o empreendedorismo são aquelas que se desenvolvem, criam riqueza e elevam a qualidade de vida de seus cidadãos. Aquelas que não centralizam seus modelos na formação de empreendimentos e na melhoria das empresas criadas, são regiões que não sustentam o ritmo da competitividade $\mathrm{e}$ transformam-se em eternos locais em vias de desenvolvimento (CASTILLO, 2006).

Proporcionar um contexto social favorável à criação e desenvolvimento de novos negócios é uma empreitada generalizada que envolve atitudes dos governos, em todos os níveis, de instituições de ensino e de fomento, e outras organizações empresariais. Para Paladino (2010), a ausência deste ambiente e a falta desta cooperação desfavorecem a mentalidade empreendedora.

Ao procurar identificar as potenciais oportunidades de negócios e assumir os riscos de suas apostas, os empreendedores são os principais agentes de mudança econômica, alguém que se comporta de acordo com seus próprios valores e objetivos, independente de avaliação ou critério externo (SEN, 2000).

Na visão de Vale, Wilkinson e Amâncio (2008), esses empreendedores elaboram conceitos de negócio e produtos, geram, disseminam, aplicam as inovações, agregam valor à atividade produtiva, combinam e integram recursos novos ou antigos espalhados pelo mercado que parecem, a princípio, incompatíveis entre si. Estas atitudes estão associadas às suas capacidades

RIBEIRO, R. L.; ARAUJO, E. A. S.; OLIVEIRA, E. A. A. Q. Mentalidade empreendedora no litoral norte paulista: uma investigação com discentes de ensino superior. Revista de Empreendedorismo e Gestão de Pequenas Empresas, v.4, n.2, 2015 
de acesso às oportunidades do mercado, através de uma rede de laços e conexões, ao contexto em que vivem e às suas mentalidades empreendedoras.

Desta forma, observar esta mentalidade com relação ao tema empreendedorismo é crucial, porque esta posição revela a inclinação dos indivíduos ao tema, bem como seu potencial para empreender (MACULAN, 2005).

Mediante o exposto, esta pesquisa tem como objetivo investigar o grau da mentalidade empreendedora de discentes de cursos presenciais de ensino superior, concluintes em 2013, do Litoral Norte Paulista e comparar o grau da mentalidade empreendedora entre estes discentes e as amostras da população, denominada força de trabalho no Brasil (indivíduos com idade entre 18 e 64 anos), obtidas a partir do relatório GEM Brasil (período 2009 a 2012).

\section{Mentalidade empreendedora}

Depois de décadas de discussão política centrada nas grandes corporações, consideradas impulsionadoras e garantidoras do progresso econômico, do avanço tecnológico e da evolução do emprego, o debate mudou (BÖGENHOLD, 2003).

O déficit progressivo dos governos, a crescente competição dos mercados, a globalização e o uso intensivo de tecnologia nos sistemas produtivos tornaram o contexto diferente daquele pautado pela grande empresa como estrutura e base da economia e da sociedade, e configurou uma nova ordem econômica (DOLABELA, 2008).

Por consequência, o poder público reduziu o endividamento com dispensas e redução do corpo de empregados e as organizações, por meio da reengenharia, passaram a fabricar mais mercadorias com menos trabalhadores, reduziram a complexidade das suas operações e ganharam agilidade. Esta reestruturação na órbita do core business induziu à renúncia de operações de menor importância (DOLABELA, 2003; 2008).

RIBEIRO, R. L.; ARAUJO, E. A. S.; OLIVEIRA, E. A. A. Q. Mentalidade empreendedora no litoral norte paulista: uma investigação com discentes de ensino superior. Revista de Empreendedorismo e Gestão de Pequenas Empresas, v.4, n.2, 2015 
Pela perspectiva do trabalhador, a quebra do vínculo empregatício, descrito por Baron e Shane (2007) como um contrato tácito entre patrão e empregado, proporcionado pela reorganização abordada acima, fez com que o funcionário renunciasse a sua fidelidade ao empregador. Como o acordo de "estabilidade" não existe mais, por que não trabalhar para si próprio?

Neste novo cenário, conclui Dolabela (2008), os micros e pequenos novos empreendimentos aparecem como responsáveis pela criação da maioria dos postos de trabalho, pela inovação e pelo crescimento das exportações. A partir disso, a discussão política aborda com mais interesse o emprego por conta própria e, como consequência, os pequenos e médios negócios frutos desta iniciativa empreendedora (BÖGENHOLD, 2003).

Desde então, a figura do empreendedor conquista o cerne das discussões sobre as formas de impulsionar o desenvolvimento das nações (LOPES, 2010). Essa nova disposição econômica reformula a figura do sujeito tradicional do período industrial. Bögenhold (2003) esclarece que quando esse sujeito começa a trabalhar por conta própria, gera pelo menos um emprego para si mesmo. Se o negócio cresce e contrata outra pessoa, produz-se um efeito multiplicador com efeitos diretos e indiretos sobre o mercado de trabalho.

Os principais ingredientes para prosperar esses e outros negócios, que favorecem o crescimento econômico e social, são o ambiente ofertado por um país para a geração e desenvolvimento de novos empreendimentos e a existência de uma mentalidade favorável dos indivíduos à atividade empreendedora (GRECO, 2011).

Greco et al. (2010) definem a mentalidade empreendedora como a postura de uma população revelada através do juízo e da percepção sobre este fenômeno econômico, social e cultural que é o empreendedorismo. Segundo esses autores, a avaliação da mentalidade empreendedora é fundamental porque manifesta a sensibilidade universal da população para com os empreendedores e suas empresas.

De acordo com Hisrich e Peters (2004), a mentalidade empreendedora contém em seus limites a probabilidade de o indivíduo detectar, atuar e mover-

RIBEIRO, R. L.; ARAUJO, E. A. S.; OLIVEIRA, E. A. A. Q. Mentalidade empreendedora no litoral norte paulista: uma investigação com discentes de ensino superior. Revista de Empreendedorismo e Gestão de Pequenas Empresas, v.4, n.2, 2015 
se mesmo em circunstâncias incertas. Para Schumpeter (1961), sob estas condições, a atividade empreendedora se manifesta sem planejar todos os detalhes do que se precisa realizar.

Maculan (2005) entende a mentalidade empreendedora como a disposição de uma pessoa, ou um conjunto delas, em aceitar a responsabilidade de fazer inversões em uma empresa financeiramente viável a partir de uma nova disposição de recursos.

Todavia, além dos requisitos individuais, é preciso ressaltar a interferência do comportamento social na mentalidade empreendedora. "Há certamente a necessidade de avaliar a importância da mentalidade empreendedora entendida não somente na sua expressão cultural $\mathrm{e}$ psicológica, mas também na sua dimensão social" (MACULAN, 2005, p. 502).

Quando uma sociedade reconhece como um de seus valores a importância das ações referentes à geração de novos negócios, mais indivíduos são sensibilizados pelo empreendedorismo. Em sua definição, Dolabela $(2003 ; 2008)$ demonstra esta ênfase no ambiente e na composição da mentalidade empreendedora, além das habilidades individuais do empreendedor. De acordo com o autor, a mentalidade empreendedora:

[...] é um potencial de qualquer ser humano e necessita de algumas condições indispensáveis para se materializar e produzir efeitos. Entre essas condições indispensáveis estão o ambiente macro, a democracia, a cooperação e a estrutura de poder tendendo para a forma de rede (DOLABELA, 2003, p. 24).

Para Greco (2011) e Hisrich e Peters (2004), o processo de empreender em uma região deriva de atores capacitados em vislumbrarem oportunidades no meio em que vivem, de converterem essas oportunidades em empreendimentos reais e da habilidade de transporem os obstáculos que impedem a criação da nova empresa.

Nos países desprovidos de alternativas de emprego, onde empreender não recompensa, ou não é visto como uma boa escolha de carreira, ser empregado passa a ser a alternativa mais natural. Nestes países, os indivíduos

RIBEIRO, R. L.; ARAUJO, E. A. S.; OLIVEIRA, E. A. A. Q. Mentalidade empreendedora no litoral norte paulista: uma investigação com discentes de ensino superior. Revista de Empreendedorismo e Gestão de Pequenas Empresas, v.4, n.2, 2015 
calculam o custo das oportunidades para empreender e confrontam o retorno esperado do novo negócio à alternativa mais habitual: ser empregado (GRECO et al., 2010; MACHADO et al., 2010).

Em sentido oposto, as nações necessitam de pessoas que identifiquem as oportunidades de negócio e que possuam as habilidades necessárias para explorá-las. Quando as condutas de um conjunto dos membros de uma coletividade frente ao novo empreendimento são afirmativas, provocam uma teia de suporte e benefícios importantes para os atuais empreendedores e para aqueles que imaginam começar uma empresa (MACHADO et al., 2010).

Para potencializar a ação desses empreendedores, como organismos facilitadores e propagadores de políticas, as diversas esferas governamentais necessitam envidar todos os esforços para conseguir disseminar uma cultura em direção à criação de negócios e à melhoria da competitividade das empresas existentes. Além das políticas de governo, as instituições de ensino, o mercado financeiro, os veículos de comunicação e a sociedade como um todo precisam dirigir suas energias para um pacto que leve à dispersão da mentalidade empreendedora (CASTILLO, 2006). North (1993) acrescenta que as instituições determinam as oportunidades que existem em uma sociedade e que as diversas organizações de uma sociedade são criadas para aproveitálas.

Um passo em direção à disseminação da mentalidade empreendedora e como principal foco de estudo e de comunicação de informações sobre empreendedorismo no mundo é o nascimento do projeto de pesquisa do Global Entrepreneurship Monitor (GEM), em 1999. Sendo assim, é essencial compreender um pouco mais deste projeto.

\section{O Global Entrepreneurship Monitor e a mentalidade empreendedora}

Fruto da parceria entre o Babson College (Massachusetts, Boston, Estados Unidos) e a London Business School (GRECO, 2011), a pesquisa

RIBEIRO, R. L.; ARAUJO, E. A. S.; OLIVEIRA, E. A. A. Q. Mentalidade empreendedora no litoral norte paulista: uma investigação com discentes de ensino superior. Revista de Empreendedorismo e Gestão de Pequenas Empresas, v.4, n.2, 2015 
GEM "[...] foi concebida como uma avaliação abrangente do papel do empreendedorismo como principal propulsor do crescimento econômico" (GRECO et al., 2010, p. 214).

Em 1999, o projeto englobava 10 países e em 2011, atingiu 54 países, de acordo com Greco (2011). O Brasil participa do estudo desde 2000 e o relatório, denominado Empreendedorismo no Brasil, é uma publicação conjunta do Consórcio GEM e do Instituto Brasileiro da Qualidade e Produtividade (IBQP). O propósito fundamental deste relatório é medir o envolvimento das pessoas na criação de empresas, ou seja, o empreendedor em período inicial.

O padrão utilizado nessa aferição é a Total Entrepreneurial Activity Atividade Empreendedora Total (TEA), traduzida por taxa de empreendedores em estágio inicial, isto é, o percentual de indivíduos da população brasileira envolvidos no processo de iniciar um novo empreendimento, assim como aqueles que estão operando uma empresa há menos de 42 meses (GRECO, 2011).

O estudo das afirmativas sobre a mentalidade empreendedora, entre outros aspectos abordados pelo relatório integral, entrevista indivíduos com idade entre 18 e 64 anos, conjunto definido pelo GEM como força de trabalho. Teve início em 2009, com 54 países. As edições de 2010 e 2011 contemplaram o mesmo número de países da edição de 2009 e em 2012, 69 países foram considerados pelo estudo. No Brasil, a pesquisa entrevistou 2.000 pessoas nas edições de 2009, 2010 e 2011, e 10.000 pessoas na edição de 2012 (GRECO et al., 2010; GRECO, 2011; GRECO, 2012).

A Tabela 1 abaixo compara o percentual de respostas afirmativas que constroem a mentalidade empreendedora no Brasil e na média dos países incluídos no projeto GEM.

De acordo com esta tabela, exceto no componente conhecimento de empreendedores, a mentalidade empreendedora no Brasil, auferida a partir das afirmativas que a compõem, é superior à média dos países consultados no projeto, principalmente levando em consideração os componentes,

RIBEIRO, R. L.; ARAUJO, E. A. S.; OLIVEIRA, E. A. A. Q. Mentalidade empreendedora no litoral norte paulista: uma investigação com discentes de ensino superior. Revista de Empreendedorismo e Gestão de Pequenas Empresas, v.4, n.2, 2015 
empreendedorismo como opção de carreira, elevado status dos

empreendedores de sucesso e atenção da mídia para o empreendedorismo.

Para Schlemm et al. (2007), esse estudo do GEM, entre outras considerações, demonstra que a mentalidade empreendedora e, como decorrência, o potencial de abertura de novas empresas estão sujeitos às variáveis sociais manifestadas no entendimento e nas posturas dos indivíduos que vivem em determinada região.

Tabela 1 - Percentual de respostas afirmativas

\begin{tabular}{|c|c|c|c|c|c|c|c|c|}
\hline Mentalidade Empreendedora & \multicolumn{4}{|c|}{ Brasil } & \multicolumn{4}{|c|}{ Média (países) } \\
\hline Componentes & 2009 & 2010 & $\begin{array}{c}201 \\
1\end{array}$ & $\begin{array}{c}201 \\
2\end{array}$ & $\begin{array}{c}200 \\
9\end{array}$ & $\begin{array}{c}201 \\
0\end{array}$ & $\begin{array}{c}201 \\
1\end{array}$ & $\begin{array}{c}201 \\
2\end{array}$ \\
\hline $\begin{array}{l}\text { Conhecimento } \\
\text { Empreendedores }\end{array}$ & $36 \%$ & $--^{4}$ & $39 \%$ & $34 \%$ & $38 \%$ & -- & $35 \%$ & $38 \%$ \\
\hline Percepção da Oportunidade & $48 \%$ & $48 \%$ & $43 \%$ & $50 \%$ & $38 \%$ & $43 \%$ & $40 \%$ & $42 \%$ \\
\hline Percepção da Capacidade & $57 \%$ & $58 \%$ & $53 \%$ & $54 \%$ & $59 \%$ & $56 \%$ & $52 \%$ & $51 \%$ \\
\hline Medo do Fracasso & $30 \%$ & $33 \%$ & $35 \%$ & $35 \%$ & $33 \%$ & $32 \%$ & $37 \%$ & $38 \%$ \\
\hline $\begin{array}{l}\text { Empreendedorismo como } \\
\text { Opção de Carreira }\end{array}$ & $80 \%$ & $78 \%$ & $86 \%$ & $88 \%$ & $72 \%$ & $73 \%$ & $70 \%$ & $66 \%$ \\
\hline $\begin{array}{l}\text { Elevado Status dos } \\
\text { Empreendedores de Sucesso }\end{array}$ & $79 \%$ & $79 \%$ & $86 \%$ & $85 \%$ & $72 \%$ & $70 \%$ & $69 \%$ & $71 \%$ \\
\hline $\begin{array}{l}\text { Atenção da Mídia para o } \\
\text { Empreendedorismo }\end{array}$ & $78 \%$ & $81 \%$ & $82 \%$ & $85 \%$ & $64 \%$ & $63 \%$ & $60 \%$ & $51 \%$ \\
\hline
\end{tabular}

Outros autores também apresentam contribuições relevantes ao debate sobre a mentalidade empreendedora no Brasil. Lima, Lopes e Nassif (2012) analisaram uma pesquisa realizada em 37 instituições brasileiras sobre a alternativa de carreira que 25.867 estudantes de Ensino Superior pretendiam trilhar. O objetivo deste estudo era identificar desafios e oportunidades para aprimorar o Ensino Superior em empreendedorismo, levando em conta, entre outros aspectos, a intenção empreendedora dos estudantes.

Logo após a conclusão do curso, grande parte dos alunos (30\% aproximadamente) demonstrou inclinação para trabalhar em médias e grandes empresas e uma pequena parcela (9\%) mostrou simpatia pela escolha de

${ }^{4}$ Afirmativa não considerada no estudo no ano de 2010.

RIBEIRO, R. L.; ARAUJO, E. A. S.; OLIVEIRA, E. A. A. Q. Mentalidade empreendedora no litoral norte paulista: uma investigação com discentes de ensino superior. Revista de Empreendedorismo e Gestão de Pequenas Empresas, v.4, n.2, 2015 
alguma atividade empreendedora. Após cinco anos de formação, a parcela de alunos com inclinação para trabalhar em médias e grandes empresas reduziu um terço e a parte dos alunos simpáticos a atividades empreendedoras dobrou (LIMA; LOPES; NASSIF, 2012).

Além dessa alteração na intenção dos indivíduos, uma característica que impressiona nas sociedades de formação recente, assim como o Brasil, é a ousadia na procura pela sobrevivência econômica. O brasileiro é um povo ousado, particularidade vital na fundação de novos negócios, associada a diferentes componentes de riscos. Em adição, no Brasil, muitas necessidades estão insatisfeitas, ainda há muitas oportunidades não identificadas e, portanto, muitos espaços para potenciais empreendedores (SCHLEMM et al., 2007).

Após identificar a mentalidade empreendedora, Bedê (2010) deduz ser factível aumentar o contingente e aperfeiçoar a qualidade dos empreendedores que vivem em determinada localidade, por intermédio de programas de propagação do empreendedorismo e pelo desenvolvimento dos atributos empreendedores na população.

Para melhor compreensão da mentalidade empreendedora na definição do GEM, esta pesquisa separa e analisa os seus componentes.

\section{Componentes da mentalidade empreendedora segundo o Global Entrepreneurship Monitor}

Especificar a extensão da mentalidade empreendedora passa por avaliar o conhecimento dos indivíduos sobre: a abertura de empresas e outros empreendedores, a percepção de oportunidade de negócios e da capacidade individual, o medo de fracassar na atividade empreendedora, a avaliação do empreendedorismo como opção de carreira, o respeito e o status perante a sociedade daqueles que alcançam sucesso ao começar um novo empreendimento e a atenção dos veículos de comunicação sobre novos negócios exitosos (GRECO, 2012).

RIBEIRO, R. L.; ARAUJO, E. A. S.; OLIVEIRA, E. A. A. Q. Mentalidade empreendedora no litoral norte paulista: uma investigação com discentes de ensino superior. Revista de Empreendedorismo e Gestão de Pequenas Empresas, v.4, n.2, 2015 
O texto a seguir descreve esses sete componentes da mentalidade empreendedora. Embora a descrição retrate-os isoladamente, verifica-se uma interdependência entre eles.

O primeiro componente é conhecer pessoalmente alguém que começou algum novo negócio nos últimos dois anos. Se as pessoas conhecem mais empreendedores em sua região, a legitimidade e o peso social do empreendedor no cerne desta localidade são afetados (MACHADO et al., 2010). Por isso, um maior conhecimento de empreendedores afeta a mentalidade empreendedora de determinado local.

Outro componente é perceber, para o semestre seguinte, boas oportunidades para empreender no local onde se vive. Para Greco et al. (2010), a força empreendedora de um país procede de pessoas que percebem a oportunidade de começar um empreendimento na região onde habitam. Dessa maneira, uma percepção elevada aumenta a força empreendedora de uma região. Ou como descrito por Bastos Junior et al. (2005, p. 30), "num contexto de economia emergente, quando o ambiente econômico é favorável, abre-se espaço àqueles que desejam principiar novos negócios em face das demandas geradas pelo aquecimento do mercado".

Este ambiente reflete a quantidade e qualidade dessa oportunidade (GRECO et al., 2010). Baron e Shane (2007) esclarecem que a forma de explorar as oportunidades tem o poder de criar valor econômico e estas oportunidades são julgadas como desejáveis nos locais onde aparecem.

$\mathrm{Na}$ verdade, desenvolver uma mentalidade empreendedora é desenvolver os parâmetros, os modelos e os requisitos que distinguem a oportunidade da ideia. As boas ideias são triviais e estão em todos os locais, porém boas oportunidades são raras (TIMMONS; SPINELLI, 2010).

O terceiro componente é ter a habilidade, a experiência e o conhecimento necessários para começar um novo negócio. Quando o indivíduo percebe que tem condições de realizar determinada tarefa, de começar uma empresa, de transformar sonhos em realidade, a percepção da capacidade empreendedora e a intenção de empreender se elevam, beneficiando toda a

RIBEIRO, R. L.; ARAUJO, E. A. S.; OLIVEIRA, E. A. A. Q. Mentalidade empreendedora no litoral norte paulista: uma investigação com discentes de ensino superior. Revista de Empreendedorismo e Gestão de Pequenas Empresas, v.4, n.2, 2015 
sociedade com a criação de empregos. Confiar em si próprio e em suas capacidades é um aspecto favorável à mentalidade empreendedora (MACHADO et al., 2010).

McClelland (1972, p. 273) também destaca a confiança "em si próprio do homem de negócio, sua capacidade de acreditar que pode fazer muito melhor do que os fatos justificam". Em vez de confiar em estímulos externos, o indivíduo com mentalidade empreendedora elevada estabelece para si próprio, um padrão de realização e busca custosamente atingir este modelo.

O quarto componente é não empreender devido ao temor de fracassar. O medo do fracasso tem força para se opor à vontade de potenciais empreendedores de converter oportunidades em negócios (GRECO, 2011). A inclinação ao risco pode significar um papel fundamental na passagem entre o empreendedor latente e o real princípio da empresa (GRECO et al., 2010).

Do mesmo modo, Timmons e Spinelli (2010) calculam que ao iniciar uma empresa, elevados níveis de mudanças, incertezas, riscos financeiros e psicológicos estão presentes e os potenciais empreendedores arriscam não apenas suas economias pessoais, mas também suas reputações nesta empreitada. Para os autores, empreender requer uma disposição de enfrentar ameaças econômicas e pessoais de forma calculada, equilibrados com os retornos potenciais. Em virtude disso, não ter medo de ser malsucedido é um importante caminho para o verdadeiro início do negócio,

O quinto componente é considerar a abertura de uma empresa como uma alternativa desejável de carreira. Um sentimento positivo dos habitantes de determinada sociedade sobre o empreendedorismo como opção de carreira legítima e prestigiada aumenta as probabilidades destes indivíduos empreenderem (GRECO, 2011). Cada vez mais nota-se no Brasil, de acordo com Greco et al. (2010), o prestígio do self-made man como uma real escolha e não como uma fuga para a falta de ocupação.

O sexto componente é a importância do status dos empreendedores de sucesso e o sétimo é a consideração dos meios de comunicação para o empreendedorismo. Ambos trabalham de forma complementar na formação da

RIBEIRO, R. L.; ARAUJO, E. A. S.; OLIVEIRA, E. A. A. Q. Mentalidade empreendedora no litoral norte paulista: uma investigação com discentes de ensino superior. Revista de Empreendedorismo e Gestão de Pequenas Empresas, v.4, n.2, 2015 
mentalidade empreendedora. A atenção da mídia para o empreendedorismo pelos veículos locais de informação, através da exposição de relatos de iniciativas bem sucedidas em jornais, revistas, programas de rádio, TV e portais, pode formar a opinião da sociedade sobre o empreendedorismo. Logo, uma ampla manifestação da mídia sobre o assunto reforça e favorece a mentalidade empreendedora e, como consequência, eleva o status dos empreendedores de sucesso (GRECO et al., 2010). Por conseguinte, como assinalam Nuez e Górriz (2008), a função de utilidade do empreendedor depende de até que ponto a sociedade considera respeitável e prestigiosa a atividade empreendedora.

Para Baron e Shane (2007), esses componentes da mentalidade empreendedora são os principais responsáveis pela tendência de cada vez mais pessoas considerarem o empreendedorismo como uma alternativa de carreira. No dizer dos autores, os meios de comunicação estão repletos de matérias sobre empreendedores prósperos. Como consequência, paira uma atmosfera positiva e sedutora sobre a criação de um empreendimento.

Em conclusão, a atitude da população de um país ou de uma região em relação à mentalidade empreendedora é um aspecto pertinente para se entender o potencial empreendedor das pessoas e a decisão de iniciar um empreendimento (GRECO, 2012).

\section{Procedimentos metodológicos}

Nesta pesquisa foi utilizada a abordagem quantitativa na coleta e no tratamento das informações. Tal abordagem é empregada, mais frequentemente cujos objetivos são descritivos, sendo o mais indicado para quantificar opiniões e dados (OLIVEIRA, 2000).

Quanto ao objetivo, este pode ser classificado como descritivo. Estudos descritivos possuem a finalidade de descobrir a natureza de um fenômeno e conhecer os diversos aspectos do comportamento humano, tanto do indivíduo

RIBEIRO, R. L.; ARAUJO, E. A. S.; OLIVEIRA, E. A. A. Q. Mentalidade empreendedora no litoral norte paulista: uma investigação com discentes de ensino superior. Revista de Empreendedorismo e Gestão de Pequenas Empresas, v.4, n.2, 2015 
retratado isoladamente quanto de grupos (VERGARA, 2005). Neste trabalho, a particularidade da conduta humana que se pretendeu descobrir foi a mentalidade empreendedora, julgada tanto no indivíduo (discente) quanto no coletivo (discentes do Litoral Norte Paulista).

Em relação ao ambiente, esta pesquisa pode ser classificada como sendo de campo. Marconi e Lakatos (2010) definem a pesquisa de campo como aquela usada com o intuito de revelar fenômenos e levantar informações ou conhecimentos para dar resposta a um problema.

A área de realização da pesquisa foi a Microrregião ou Sub-Região de Caraguatatuba, ou Litoral Norte Paulista, que vive, atualmente, um momento de convergência de fatores políticos, demográficos, sociais e, principalmente, econômicos, devido aos investimentos públicos estaduais e federais que a região vem recebendo, tais como: a construção da Unidade de Tratamento de Gás de Caraguatatuba para exploração de gás natural da Bacia de Mexilhão; a duplicação da Rodovia dos Tamoios - SP-55, a estrada mais importante da região; e a futura ampliação do Porto de São Sebastião (RIBEIRO et al., 2013). Estes motivos determinaram a escolha da região como foco da pesquisa.

Em 2010 a economia da região apresentava a seguinte divisão: da composição total do PIB (Produto Interno Bruto), de aproximadamente 5,9 bilhões de reais, a participação do setor de serviços, incluindo o comércio, foi de 2,40 bilhões de reais ou 40,4\%, a participação da administração pública foi de 840 milhões de reais ou $14,1 \%$, a participação do setor agropecuário foi de 34 milhões de reais ou $0,5 \%$, a participação do setor industrial foi de 608 milhões de reais ou $10,2 \%$ e as transferências de impostos sobre produtos líquidos de subsídios foi de 2,06 bilhões de reais ou 34,7\% (IBGE, 2014; SEADE, 2013).

O Litoral Norte Paulista é composto pelos municípios de Caraguatatuba, Ilhabela, São Sebastião e Ubatuba. Foram consideradas todas as Instituições de Ensino Superior (IES), públicas e privadas, situadas na região, que oferecem ensino presencial, totalizando quatro instituições.

RIBEIRO, R. L.; ARAUJO, E. A. S.; OLIVEIRA, E. A. A. Q. Mentalidade empreendedora no litoral norte paulista: uma investigação com discentes de ensino superior. Revista de Empreendedorismo e Gestão de Pequenas Empresas, v.4, n.2, 2015 
A população desta pesquisa tem como característica comum, ser aluno concluinte em 2013, nos cursos presenciais das IESs da região. Este grupo foi selecionado, pois no dizer de Liñan e Rodríguez-Cohard (2004), o segmento da população que tende a apresentar o mais alto potencial empreendedor é aquele constituído por jovens adultos com Ensino Superior. Assim, esta pesquisa está centrada na investigação de alunos universitários do último ano, devido ao nível universitário e à faixa etária.

Vergara (2005) conceitua a amostra como a parcela do universo selecionada a partir de um critério significativo. Nesta pesquisa, o critério empregado relevante foi a facilidade de abordar os discentes nos dias regulares de aula, dentro das classes, em datas pré-acordadas com a coordenação e com a direção das IESs.

O tamanho da amostra em todas as populações está representado pela equação (REA; PARKER, 2000):

$$
n=\frac{Z^{2} \alpha(0,25) N}{Z^{2} \alpha(0,25)+(N-1) C^{2} p}
$$

Onde:

Z = nível de confiança. (Quando o nível de confiança for 95\%, Z é igual a $1,96)$

$\mathrm{N}$ = tamanho da população

$\mathrm{Cp}=$ margem de erro

Como esta pesquisa adotou um nível de confiança de 95\%, o tamanho da população era de 437 indivíduos e a margem de erro foi de $5 \%$. A equação para calcular o tamanho da amostra, neste caso, foi:

$$
n=\frac{1,96^{2} \alpha(0,25) 437}{1,96^{2} \alpha(0,25)+(437-1) 0,05^{2}}
$$

RIBEIRO, R. L.; ARAUJO, E. A. S.; OLIVEIRA, E. A. A. Q. Mentalidade empreendedora no litoral norte paulista: uma investigação com discentes de ensino superior. Revista de Empreendedorismo e Gestão de Pequenas Empresas, v.4, n.2, 2015 
O resultado da equação e, consequentemente, o tamanho mínimo desta amostra é de 205 indivíduos. A pesquisa interpelou 259 discentes.

Neste caso, o tipo da amostra foi a não probabilística e a técnica de amostragem foi determinada por acessibilidade. A técnica por acessibilidade "[...] seleciona elementos pela facilidade de acesso a eles" (VERGARA, 2005, p. 51). A opção pela amostra não probabilística por acessibilidade foi fruto da origem e local de trabalho dos alunos, localização das IESs e da oferta dos cursos.

O instrumento de coleta de dados foi o questionário, aplicado em contato direto com os entrevistados e organizado com perguntas fechadas dicotômicas (sim ou não). As perguntas fechadas são aquelas em que o entrevistado está limitado às opções restritas do questionário, sem permissão de emitir opiniões (MARCONI; LAKATOS, 1999; 2010). No intuito de testar o instrumento elaborado anteriormente à coleta, aplicou-se um pré-teste do questionário, nas mesmas condições previstas para a realização da pesquisa, com discentes concluintes em 2013 de cursos presenciais que fazem parte do universo escolhido. Os dados dos discentes selecionados nesta fase não participaram da etapa posterior.

As questões abrangeram os conceitos específicos e as descrições das medidas da mentalidade empreendedora. Utilizou-se como referência, o estudo do Global Entrepreneurship Monitor (GEM). Este estudo objetiva medir o grau da mentalidade empreendedora e entrevistam-se membros da população adulta entre 18 e 64 anos dos países integrantes da análise. Segundo este estudo, quanto maior o percentual de respostas afirmativas, maior o grau da mentalidade empreendedora.

Submeteram-se aos discentes as afirmativas sobre a mentalidade empreendedora. Ao final, somaram-se as respostas afirmativas e as negativas. Quanto maior o número de afirmativas positivas, maior o grau da mentalidade empreendedora.

A aplicação do questionário ocorreu entre agosto e setembro de 2013, mediante a autorização da direção das IESs, a permissão dos professores para

RIBEIRO, R. L.; ARAUJO, E. A. S.; OLIVEIRA, E. A. A. Q. Mentalidade empreendedora no litoral norte paulista: uma investigação com discentes de ensino superior. Revista de Empreendedorismo e Gestão de Pequenas Empresas, v.4, n.2, 2015 
a aplicação da pesquisa nos dias específicos e a quantidade de alunos em classe nos dias determinados.

Para o tratamento de dados, utilizou-se da estatística descritiva com atenção às medidas de tendência central e de dispersão, acompanhando os mesmos procedimentos do estudo do GEM.

\section{Resultados e discussões}

Os resultados a seguir quantificam a mentalidade empreendedora dos discentes de Ensino Superior de cursos presenciais, concluintes em 2003, das IESs do Litoral Norte Paulista.

A Tabela 2 reúne o percentual de respostas afirmativas dos discentes. De acordo com esta tabela, todos os componentes da mentalidade empreendedora apresentaram percentuais de respostas positivas maiores que o percentual de respostas negativas. Vale ressaltar que, segundo o modelo GEM, quanto maior o percentual de respostas afirmativas, maior o grau da mentalidade empreendedora.

Tabela 2 - Percentual de Respostas Afirmativas - Discente

\section{Mentalidade Empreendedora}

Total

\begin{tabular}{lc}
\hline $\begin{array}{l}\text { Você conhece pessoalmente alguém que começou um novo negócio nos } \\
\text { últimos dois anos? }\end{array}$ & $80 \%$ \\
\hline $\begin{array}{l}\text { Você percebe para os próximos seis meses boas oportunidades para se } \\
\text { começar um novo negócio na região em que vive? }\end{array}$ & $59 \%$ \\
\hline $\begin{array}{l}\text { Você tem o conhecimento, a habilidade e a experiência necessária para se } \\
\text { começar um novo negócio? }\end{array}$ & $53 \%$ \\
\hline O medo de fracassar impediria que começasse um negócio? & $36 \%$ \\
\hline $\begin{array}{l}\text { Em meu país, a maioria das pessoas considera a abertura, o início de um } \\
\text { negócio como uma opção desejável de carreira? }\end{array}$ & $72 \%$ \\
\hline $\begin{array}{l}\text { Em meu país, aqueles que alcançam sucesso ao iniciar um novo negócio têm } \\
\text { prestígio e respeito perante a sociedade? }\end{array}$ & $87 \%$ \\
\hline $\begin{array}{l}\text { Em meu país, observa-se frequentemente na mídia histórias sobre novos } \\
\text { negócios bem sucedidos? }\end{array}$ & $71 \%$ \\
\hline
\end{tabular}

Fonte: Elaborado pelos autores (2015)

RIBEIRO, R. L.; ARAUJO, E. A. S.; OLIVEIRA, E. A. A. Q. Mentalidade empreendedora no litoral norte paulista: uma investigação com discentes de ensino superior. Revista de Empreendedorismo e Gestão de Pequenas Empresas, v.4, n.2, 2015 
Os componentes "conhecimento de empreendedores" e "elevado status dos empreendedores de sucesso" atingiram percentuais expressivos de respostas afirmativas, $80 \%$ e $87 \%$. Respectivamente, "empreendedorismo como opção de carreira" e "atenção da mídia para o empreendedorismo" alcançaram percentuais elevados, todos em torno de $70 \%$.

A interpretação do componente "medo do fracasso" é inversa ao demais e conseguiu um percentual elevado: apenas 36\% dos discentes têm medo de fracassar ao empreender. Exposto de outra forma, o medo de fracassar não é obstáculo para $64 \%$ dos discentes iniciarem um negócio. $E$, finalmente, os componentes "percepção da oportunidade" e "percepção da capacidade" obtiveram percentuais maiores de respostas afirmativas do que de respostas negativas, $59 \%$ e $53 \%$ respectivamente.

A natureza sociocultural do empreendedorismo é um fenômeno repleto de aspectos e atitudes comportamentais, que se modifica de uma região para outra (EMMENDOERFER; FONSECA, 2005) e o potencial de criação de novas empresas está submetido aos elementos sociais manifestados no entendimento e na posição dos indivíduos que vivem em determinado local (SCHLEMM et al., 2007).

Por tais razões, esta pesquisa comparou os resultados dos discentes do Litoral Norte com os resultados do estudo GEM realizado com pessoas entre 18 e 64 anos que integram a força de trabalho no Brasil, entre 2009 e 2012, denominada aqui como amostra GEM Brasil. Para melhor compreensão, os resultados foram divididos e comparados com as amostras GEM Brasil em cada componente da mentalidade empreendedora.

De acordo com a Tabela 3, 80\% dos discentes do Litoral Norte Paulista conhecem alguém que começou algum negócio nos últimos dois anos. Nas amostras GEM Brasil, este percentual não atinge 40\%.

RIBEIRO, R. L.; ARAUJO, E. A. S.; OLIVEIRA, E. A. A. Q. Mentalidade empreendedora no litoral norte paulista: uma investigação com discentes de ensino superior. Revista de Empreendedorismo e Gestão de Pequenas Empresas, v.4, n.2, 2015 
Tabela 3 - Conhecimento de Empreendedores - Amostra GEM Brasil x Discente

\begin{tabular}{l|c|c|c|c|c}
\hline \multicolumn{1}{c|}{ Região } & \multicolumn{4}{|c|}{ Amostra GEM Brasil } & Discente \\
\hline Ano & 2009 & 2010 & 2011 & 2012 & 2013 \\
\hline Conhecimento de Empreendedores & $36 \%$ & -- & $39 \%$ & $34 \%$ & $80 \%$ \\
\hline
\end{tabular}

Fonte: Elaborado pelos autores a partir de Greco (2012); Greco (2011); Greco et al (2010); Machado et al (2010).

Este percentual de respostas afirmativas sobre o conhecimento de empreendedores é elevado em relação ao Brasil e colabora com a mentalidade empreendedora da região, indicando um cotidiano afetado pela iniciativa empreendedora. Conforme Schlemm et al. (2007) escrevem, os exemplos de vida corroboram o espírito empreendedor e novos negócios produzem novos negócios.

Ademais, o resultado indica que o empreendedor tem força e a legitimidade mais elevadas no Litoral Norte Paulista do que no Brasil, porque, como relembram Machado et al. (2010), quanto mais empreendedores os indivíduos conhecem, maiores conhecimentos sobre a carreira, fundamentos e peso social do empreendedor no seio de certa região.

Segundo a Tabela 4, 59\% dos discentes percebem boas oportunidades de negócios para os próximos seis meses no Litoral Norte Paulista. Nas amostras GEM Brasil, o percentual atinge no máximo 50\%. Este número é favorável à mentalidade empreendedora dos discentes.

Tabela 4 - Percepção da Oportunidade - Amostra GEM Brasil x Discente

\begin{tabular}{l|c|c|c|c|c}
\hline \multicolumn{1}{c|}{ Região } & \multicolumn{4}{c|}{ Amostra GEM Brasil } & Discente \\
\hline Ano & 2009 & 2010 & 2011 & 2012 & 2013 \\
\hline Percepção da Oportunidade & $48 \%$ & $48 \%$ & $43 \%$ & $50 \%$ & $59 \%$ \\
\hline
\end{tabular}

Fonte: Elaborado pelos autores a partir de Greco (2012); Greco (2011); Greco et al (2010); Machado et al (2010).

A estabilidade econômica que o Brasil vem conquistando exibe um contexto encorajador para empreendedores e sociedade, mesmo que a um custo de um progresso econômico tímido, comparado com outros países em mesmo estágio de desenvolvimento (GRECO, 2006). Este cenário contagiou os brasileiros e os discentes do Litoral Norte Paulista igualmente.

RIBEIRO, R. L.; ARAUJO, E. A. S.; OLIVEIRA, E. A. A. Q. Mentalidade empreendedora no litoral norte paulista: uma investigação com discentes de ensino superior. Revista de Empreendedorismo e Gestão de Pequenas Empresas, v.4, n.2, 2015 
Timmons e Spinelli (2010) relatam que ideias triviais estão por toda parte, mas boas oportunidades de negócios são raras e que é a mentalidade empreendedora que transforma as oportunidades em valor econômico.

Neste sentido, o potencial empreendedor depende de indivíduos que percebam as escassas e viáveis oportunidades para iniciar um negócio no local onde vivem (GRECO et al., 2010). O Litoral Norte Paulista dispõe de discentes dispostos e inspirados que reconhecem essas oportunidades, mais do que os integrantes da amostra Brasil.

A causa principal do empreendedorismo é o encontro entre pessoas empreendedoras, com disposição, conhecimento (que se reconhecem preparadas) e oportunidades valiosas. Para Baron e Shane (2007), nada se torna realidade em relação a essas oportunidades até o momento em que uma pessoa decidida e inspirada descubra-as e explore-as.

A Tabela 5 estima que, aproximadamente, metade dos discentes, $53 \%$, afirma ter o conhecimento, a habilidade e a experiência necessários para começar um empreendimento, percentual muito próximo aos das amostras GEM Brasil.

Tabela 5 - Percepção da Capacidade - Amostra GEM Brasil x Discente

\begin{tabular}{l|c|c|c|c|c}
\hline \multicolumn{1}{c|}{ Região } & \multicolumn{4}{c|}{ Amostra GEM Brasil } & Discente \\
\hline Ano & 2009 & 2010 & 2011 & 2012 & 2013 \\
\hline Percepção da Capacidade & $57 \%$ & $58 \%$ & $53 \%$ & $54 \%$ & $53 \%$ \\
\hline
\end{tabular}

Fonte: Elaborado pelos autores a partir de Greco (2012); Greco (2011); Greco et al. (2010); Machado et al. (2010).

Esta percepção da própria capacidade reforça a mentalidade empreendedora dos discentes do Litoral Norte Paulista, pois Machado et al. (2010) destacam que a confiança em si e nas suas competências e habilidades é um fator favorável à mentalidade empreendedora. Quando um indivíduo percebe que tem capacidade de realizar algo, de iniciar um negócio, a manifestação da mentalidade empreendedora cresce e, se traduzida em ação, favorece toda a região com a criação de empregos.

RIBEIRO, R. L.; ARAUJO, E. A. S.; OLIVEIRA, E. A. A. Q. Mentalidade empreendedora no litoral norte paulista: uma investigação com discentes de ensino superior. Revista de Empreendedorismo e Gestão de Pequenas Empresas, v.4, n.2, 2015 
A Tabela 6 revela que o medo de fracassar impediria 36\% dos discentes de abrir um negócio, praticamente as mesmas taxas das amostras GEM Brasil. Em outras palavras, o medo de fracassar não impediria $64 \%$ dos discentes de abrir seu próprio negócio.

Tabela 6 - Medo do Fracasso - Amostra GEM Brasil x Discente

\begin{tabular}{l|c|c|c|c|c}
\hline \multicolumn{1}{c|}{ Região } & \multicolumn{4}{|c|}{ Amostra GEM Brasil } & Discente \\
\hline Ano & 2009 & 2010 & 2011 & 2012 & 2013 \\
\hline Medo do Fracasso & $30 \%$ & $33 \%$ & $35 \%$ & $35 \%$ & $36 \%$ \\
\hline
\end{tabular}

Fonte: Elaborado pelos autores a partir de Greco (2012); Greco (2011); Greco et al. (2010); Machado et al. (2010).

A propensão ao risco pode desempenhar um papel fundamental na transição entre o potencial empreendedor e o concreto início do negócio (GRECO et al., 2010). Greco (2011) explica que o medo do fracasso tem peso para se contrapor à vontade de empreendedores latentes de transformar oportunidades em empresas reais. Isto porque, além das finanças pessoais, estes empreendedores arriscam, inclusive, o conceito que eles gozam dentro da sociedade a qual pertencem (TIMMONS; SPINELLI, 2010).

Os discentes do Litoral Norte Paulista, assim como as amostras GEM Brasil, não têm medo de arriscar nem seus recursos financeiros, nem seu patrimônio social, caso decidam iniciar a carreira empreendedora. No caso dos discentes, como são jovens em início de carreira (44\% com idade até 24 anos), solteiros com poucos compromissos familiares, com apoio da família e amigos, e cercados de modelos inspiradores, o fracasso não aparenta ser um temor, o que favorece a mentalidade empreendedora.

A admiração da carreira de empreendedor é maior entre a população das amostras GEM Brasil do que entre os discentes, 72\%. Mesmo assim, a Tabela 7 retrata que a maioria deles considera a criação de um negócio como uma opção desejável de carreira, outra resposta favorável à mentalidade empreendedora.

RIBEIRO, R. L.; ARAUJO, E. A. S.; OLIVEIRA, E. A. A. Q. Mentalidade empreendedora no litoral norte paulista: uma investigação com discentes de ensino superior. Revista de Empreendedorismo e Gestão de Pequenas Empresas, v.4, n.2, 2015 
Tabela 7 - Empreendedorismo como Opção de Carreira - Amostra GEM Brasil x Discente

\begin{tabular}{l|cccc|c}
\hline \multicolumn{1}{c|}{ Região } & \multicolumn{4}{|c|}{ Amostra GEM Brasil } & Discente \\
\hline Ano & 2009 & 2010 & 2011 & 2012 & 2013 \\
\hline Empreendedorismo como Opção de Carreira & $80 \%$ & $78 \%$ & $86 \%$ & $88 \%$ & $72 \%$ \\
\hline
\end{tabular}

Fonte: Elaborado pelos autores a partir de Greco (2012); Greco (2011); Greco et al. (2010); Machado et al. (2010).

Embora apresente um percentual elevado de respostas positivas neste componente, o percentual menor de repostas positivas em comparação com a amostra Brasil, pode estar relacionado com a característica da economia da região.

O setor econômico da Administração Pública é o segundo maior gerador de empregos no Litoral Norte Paulista. A estabilidade de emprego, proporcionada pela condição de concursado em empresa pública, pode seduzir parte dos discentes. Nos demais setores da economia local, que podem oferecer um contraponto a esta força de atração da Administração Pública, a realidade é esta: no maior empregador da região, o setor de serviços (incluído o comércio), composto essencialmente de micro e pequenas empresas, os rendimentos são baixos, exceto para alguns proprietários. Nos demais setores, Indústria e, principalmente, Agricultura, as opções de emprego são raras ou quase inexistentes, devido aos seus pesos na economia regional (SEADE, 2013; IBGE, 2014).

Apesar deste contexto, a avaliação dos discentes sobre este componente é favorável à mentalidade empreendedora. Neste caso, a disposição positiva das pessoas de uma região específica sobre 0 empreendedorismo, como alternativa de ocupação legítima e valorizada, amplia a possibilidade dessas empreenderem (GRECO, 2011).

A Tabela 8 revela que $87 \%$ dos discentes percebem o prestígio e o respeito da sociedade para com os empreendedores, muito próximo das amostras GEM Brasil.

RIBEIRO, R. L.; ARAUJO, E. A. S.; OLIVEIRA, E. A. A. Q. Mentalidade empreendedora no litoral norte paulista: uma investigação com discentes de ensino superior. Revista de Empreendedorismo e Gestão de Pequenas Empresas, v.4, n.2, 2015 
Tabela 8 - Elevado Status dos Empreendedores de Sucesso - Amostra GEM Brasil x Discente

\begin{tabular}{|c|c|c|}
\hline Região & Amostra GEM Brasil & Discente \\
\hline$\overline{A n o}$ & 2009201020112012 & 2013 \\
\hline Elevado Status dos Empreendedores de Sucesso & $\begin{array}{|llll|}79 \% & 79 \% & 86 \% & 85 \% \\
\end{array}$ & $87 \%$ \\
\hline
\end{tabular}

Fonte: Elaborado pelos autores a partir de Greco (2012); Greco (2011); Greco et al. (2010); Machado et al. (2010).

O respeito da coletividade, para aqueles que conquistam êxito ao começar um novo negócio, valoriza a mentalidade empreendedora (GRECO, 2011). Maculan (2005) e Greco (2011) salientam a interferência da valorização social na mentalidade, afora sua dimensão psicológica.

A existência de um ambiente onde o empreendedor é valorizado, em outras palavras, a possibilidade deste agente econômico obter prestígio social, propicia um entorno mais favorável ao empreendedorismo. Assim, um aumento de reconhecimento social implica em alterações nas preferências individuais (NUEZ; GÓRRIZ, 2008).

Os discentes percebem o elevado status dos empreendedores de sucesso, o respeito deles perante a sociedade e a valorização do seu papel no meio onde vivem. Tudo isto reflete positivamente na mentalidade empreendedora e nas escolhas profissionais futuras.

Embora dentro de um patamar menor do que as amostras GEM Brasil, $71 \%$, os discentes presenciam repetidamente na mídia, histórias sobre novos negócios bem sucedidos, beneficiando a mentalidade empreendedora, conforme a Tabela 9.

Tabela 9 - Atenção da Mídia para o Empreendedorismo - Amostra GEM Brasil x Discente

\begin{tabular}{l|cccc|c}
\hline \multicolumn{1}{c|}{ Região } & \multicolumn{3}{|c|}{ Amostra GEM Brasil } & Discente \\
\hline Ano & 2009 & 2010 & 2011 & 2012 & 2013 \\
\hline Atenção da Mídia para o Empreendedorismo & $78 \%$ & $81 \%$ & $82 \%$ & $85 \%$ & $71 \%$ \\
\hline
\end{tabular}

Fonte: Elaborado pelos autores a partir de Greco (2012); Greco (2011); Greco et al. (2010); Machado et al. (2010).

RIBEIRO, R. L.; ARAUJO, E. A. S.; OLIVEIRA, E. A. A. Q. Mentalidade empreendedora no litoral norte paulista: uma investigação com discentes de ensino superior. Revista de Empreendedorismo e Gestão de Pequenas Empresas, v.4, n.2, 2015 
O respeito dos meios de comunicação e informação com o empreendedorismo, a opinião da sociedade sobre o assunto torna-se mais consistente (GRECO et al., 2010). Nesse sentido, Castillo (2006) destaca a importância dos meios de comunicação na disseminação da mentalidade empreendedora.

Inegavelmente, como se observa pela quantidade de respostas positivas das amostras GEM Brasil e, em menor quantidade, pela resposta dos discentes, a mídia nacional cumpre este papel de propagadora do empreendedorismo, com pautas em telejornais e sites, inserção de matérias e cadernos semanais específicos sobre o tema em jornais de circulação nacional, revistas exclusivas sobre empreendedores brasileiros ícones, programas de rádio e de televisão, com entrevistas sobre homens de negócios, entre outros veículos especializados no assunto.

Mas no Litoral Norte Paulista, a imprensa regional torna menos consistente o juízo da comunidade sobre o empreendedorismo, pois ocupa suas páginas e colunas com pautas sobre o cotidiano do cidadão como, por exemplo, demandas e problemas das áreas da saúde, educação, esporte e transporte público, vida social, inaugurações, visitas de autoridades políticas à região, reivindicações populares diversas e a rotina policial.

Depois dessa quantificação, observa-se que o grau da mentalidade empreendedora na percepção dos discentes do Litoral Norte Paulista é maior do que na amostra Brasil. Em quatro de seus oito componentes, o percentual de respostas afirmativas dos discentes foi maior do que na amostra Brasil e em três de seus sete componentes, o percentual de respostas afirmativas da amostra Brasil foi maior do que o percentual dos discentes.

\section{Considerações finais}

No sentido de alcançar o objetivo da pesquisa, o estudo quantificou o grau da mentalidade empreendedora dos discentes. Como consequência,

RIBEIRO, R. L.; ARAUJO, E. A. S.; OLIVEIRA, E. A. A. Q. Mentalidade empreendedora no litoral norte paulista: uma investigação com discentes de ensino superior. Revista de Empreendedorismo e Gestão de Pequenas Empresas, v.4, n.2, 2015 
demonstrou, por meio de medidas percentuais e médias, que os discentes têm uma mentalidade empreendedora elevada. Quando uma região apresenta a mentalidade empreendedora em alto grau, os pilares do seu crescimento estão cravados (MELO, 2012).

O percentual de respostas positivas às afirmativas foram maiores do que as negativas em todos os componentes da mentalidade empreendedora (exceto no componente medo do fracasso, onde o cálculo é inverso).

A análise por parte dos discentes dos componentes "Conhecimento de Indivíduos Empreendedores" e a "Intenção de Empreender", despertam atenção. A expressiva diferença entre o percentual de respostas afirmativas dos discentes e da amostra Brasil, a favor dos primeiros, pode ser explicada pelo momento econômico privilegiado que o Litoral Norte Paulista passa, momento este analisado por Ribeiro et al. (2013).

A mesma explicação pode ser utilizada no estudo da vantagem, não tão expressiva quanto as anteriores, dos discentes sobre as amostras Brasil no componente "Percepção da Oportunidade". Neste caso, vale adicionar também, como justificativa da diferença, o fato do universo abranger discentes concluintes em cursos de nível superior. Durante a vida acadêmica, os discentes entram em contato com disciplinas, informações e ferramentas que facilitam a identificação de oportunidade. Embora a educação formal não possa ser encarada como o principal requisito para estimular a mentalidade empreendedora (CASTANHAR, 2007; HISRICH; PETERS, 2004), Hisrich e Peters (2004) destacam o acesso e o aumento do conhecimento como ingredientes básicos do processo de identificação de oportunidades.

O exame do percentual de respostas positivas do componente "Percepção da Capacidade", levemente acima da média, pode sinalizar que os discentes, ao final de seus programas acadêmicos, compreendem a real dimensão de abrir e administrar um empreendimento. O mesmo raciocínio se aplica na interpretação do percentual de respostas positivas do componente "Medo de Fracassar", acima da amostra Brasil, e do componente "Empreendedorismo como Opção de Carreira”, abaixo da amostra Brasil.

RIBEIRO, R. L.; ARAUJO, E. A. S.; OLIVEIRA, E. A. A. Q. Mentalidade empreendedora no litoral norte paulista: uma investigação com discentes de ensino superior. Revista de Empreendedorismo e Gestão de Pequenas Empresas, v.4, n.2, 2015 
Aliada a esta interpretação aflora outra: o pleno emprego dos discentes. Para Castanhar (2007), a decisão de tornar-se empreendedor deriva das opções de trabalho disponíveis, dos recursos passíveis de captação, das habilidades pessoais e das preferências individuais comparados com o perfil risco-retorno do indivíduo. Ser funcionário (salário certo no final do mês mais benefícios) pode ser um caminho mais atraente, mesmo que a recompensa de um negócio próprio seja maior (MACHADO et al., 2010).

Outra característica peculiar do mercado de trabalho da região causa impacto nesses dois componentes da mentalidade empreendedora: um dos maiores empregadores da região é a instituição pública. Nesta circunstância, o cargo público como opção de carreira pública concorre com o empreendedorismo como opção de carreira e o medo de fracassar na criação de um negócio significa um risco maior do que a promessa da estabilidade no setor público.

Os expressivos percentuais de respostas positivas sobre os componentes "Elevado Status dos Empreendedores de Sucesso" e "Atenção da Mídia para o Empreendedorismo", assinalam a valorização e o respeito dos discentes pela atividade empreendedora e a criação de negócios, além da consideração dos meios de comunicação com o empreendedorismo. Este comportamento, conforme Schlemm et al. (2007), tende para um cotidiano ocupado pela mentalidade empreendedora.

O empreendedorismo é um catalisador do desenvolvimento, uma força social capaz de fazer crescer uma economia. Tem como consequência, a criação de emprego, a geração de renda, o fomento da qualidade de vida e a produção de valor para a sociedade.

A mentalidade empreendedora é a atitude dos indivíduos de uma região evidenciada por meio da consciência sobre desse fenômeno que é o empreendedorismo. Ela carrega, tacitamente, uma resolução responsável de criação de um empreendimento.

Por fim, uma investigação sobre a mentalidade empreendedora é necessária em regiões como o Litoral Norte Paulista, pois indica o potencial de

RIBEIRO, R. L.; ARAUJO, E. A. S.; OLIVEIRA, E. A. A. Q. Mentalidade empreendedora no litoral norte paulista: uma investigação com discentes de ensino superior. Revista de Empreendedorismo e Gestão de Pequenas Empresas, v.4, n.2, 2015 
seus indivíduos para empreender. Depois de quantificá-la é possível capacitar os potenciais empreendedores e elevar o contingente de indivíduos dispostos a optar pelo empreendedorismo como carreira profissional. Esta atitude é essencial para a região. Através desses agentes econômicos, é possível conduzir e organizar seus esforços rumo ao seu próprio desenvolvimento. Dessa forma, a criação da empresa é a alternativa para as pessoas usufruírem do crescimento e do desenvolvimento econômico.

\section{Referências:}

BARON, R. A.; SHANE, S. A. Empreendedorismo: uma visão de processo. São Paulo: Thomson Learning, 2007.

BASTOS JUNIOR P. A. GRECO, S. M. S. S.; HOROCHOVSKI, R. R.; MACHADO, J. P.; SCHLEMM M. M. (Coords.). Empreendedorismo no Brasil: 2004. Curitiba: IBQP, 2005. Disponível em: <www.ibqp.org.br/gem>. Acesso em 25 fev. 2012.

BEDÊ, M. A. O uso de técnicas lúdicas no ensino do empreendedorismo: um estudo de caso. In: LOPES, R. M. A. (Orga.). Educação empreendedora: conceitos, modelos e práticas. Cap. 4. Rio de Janeiro: Elsevier; São Paulo: SEBRAE, 2010.

BÖGENHOLD, D. La doble cara de la capacidad empresarial: una alternativa a la noción popular. Revista de Economía Institucional. Bogotá, v. 5, n. 8, 2003.

CARVAJAL, P. F. S.; SÁNCHEZ, I, M. H.; MÉNDEZ, S. R.; LÉON RUBIO, J. M. El efecto de la conservción de recursos sobre la intención emprendedora em El contexto de crisis econômica: el rol moderador de la autoeficacia y la creatividad. Anales de Psicología, v. 29, n. 3, 2013.

CASTANHAR, J. C. Empreendedorismo e desenvolvimento regional no Brasil. Uma análise da relação entre a criação de empresas e o desenvolvimento regional ao longo do tempo e de estratégias de empreendedores selecionados [Em linha]. Lisboa: ISCTE, 2007. Tese de mestrado. [Consult. 27 jul. 2013] Disponível em www:<http://hdl.handle.net/10071/1302>. Acesso em: 27 jul. 2013. ISBN 978989-8154-51-4

CASTILLO, J. C. Espíritu empresarial como estratégia de competitividad y desarrollo econômico. Revista Escuela de Administración e Negocio. Bogotá, n. 57, 2006.

RIBEIRO, R. L.; ARAUJO, E. A. S.; OLIVEIRA, E. A. A. Q. Mentalidade empreendedora no litoral norte paulista: uma investigação com discentes de ensino superior. Revista de Empreendedorismo e Gestão de Pequenas Empresas, v.4, n.2, 2015 
DOLABELA, F. Pedagogia empreendedora. São Paulo: Editora de Cultura, 2003.

DOLABELA, F. Oficina do empreendedor. Rio de Janeiro: Sextante, 2008.

EMMENDOERFER, M. L.; FONSECA, M. R. C. M. Estratégia e planejamento como alicerces da cultura empreendedora. In: ENCONTRO DE ESTUDOS SOBRE EMPREENDEDORISMO E GESTÃO DE PEQUENAS EMPRESAS. 4. 2005, Curitiba, Anais... Curitiba, 2005.

GRECO, S. M. S. S (Coord.). Empreendedorismo no Brasil: 2005. Curitiba: IBQP, 2006. Disponível em: <www.ibqp.org.br/gem>. Acesso em: 25 fev. 2012.

GRECO, S. M. S. S (Coord.). Empreendedorismo no Brasil: 2011. Curitiba: IBQP, 2011. Disponível em: <www.ibqp.org.br/gem>. Acesso em 25 fev. 2012.

GRECO, S. M. S. S (Coord.). Empreendedorismo no Brasil: 2012. Curitiba: IBQP, 2012. Disponível em: <www.ibqp.org.br/gem>. Acesso em 25 ago. 2012.

GRECO, S. M. S. S; FRIEDLAENDER JUNIOR, R. H.; TAMADA NETO, M. (Coords.). Empreendedorismo no Brasil: 2010. Curitiba: IBQP, 2010. Disponível em: <www.ibqp.org.br/gem>. Acesso em: 25 fev. 2012.

GUERRA, M. J.; GRAZZIOTIN, Z. J. Educação empreendedora nas universidades brasileiras. In: LOPES, R. M. A. (Orga.). Educação empreendedora: conceitos, modelos e práticas. Cap. 4. Rio de Janeiro: Elsevier; São Paulo: SEBRAE, 2010.

HISRICH, R. D.; PETERS, M. P. Empreendedorismo. 5 ed. Porto Alegre: Bookman, 2004.

IBGE. Instituto Brasileiro de Geografia e Estatística. IBGE Cidades. Brasília: IBGE, 2014. Disponível em: <http://www.cidades.ibge.gov.br/xtras/home.php>. Acesso em: 25 jan. 2014.

LIMA, E.; LOPES, R. M. A.; NASSIF, V. M. J. Empreendedorismo para todos: desafios e oportunidades para aperfeiçoar a educação superior brasileira. In: ENCONTRO DA ASSOCIAÇÃO NACIONAL DE PÓS-GRADUAÇÃO E PESQUISA EM ADMINISTRAÇÃO. 36. 2012, Rio de Janeiro, Anais... Rio de Janeiro, 2012.

LIÑAN, F. RODRÍGUEZ-COHARD, J.C. Entrepreneurial attitudes of Andalusian university students. In: EUROPEAN REGIONAL SCIENCE ASSOCIATION, 2004. Disponível em: < http://ideas.repec.org/p/wiw/wiwrsa/ersa04p161.html>. Acesso em: 08 fev. 2014.

RIBEIRO, R. L.; ARAUJO, E. A. S.; OLIVEIRA, E. A. A. Q. Mentalidade empreendedora no litoral norte paulista: uma investigação com discentes de ensino superior. Revista de Empreendedorismo e Gestão de Pequenas Empresas, v.4, n.2, 2015 
LOPES, R. M. A. Referenciais para educação empreendedora. In: LOPES, R. M. A. (Orga.). Educação empreendedora: conceitos, modelos e práticas. Cap. 2. Rio de Janeiro: Elsevier; São Paulo: SEBRAE, 2010.

MACHADO, J. P.; FELIX, J. C.; GRECO, S. M. S. S.; BASTOS JUNIOR, P. A.; SILVESTRE, R. G. M.; MORAES, A. A.; CÔRTES, A. M.; FRIEDLAENDER JUNIOR, R. H.; Empreendedorismo no Brasil: 2009. Curitiba : IBQP, 2010. Disponível em: <www.ibqp.org.br/gem>. Acesso em: 25 fev. 2012.

MACULAN, A. M. Analisando o empreendedorismo. In: ENCONTRO DE ESTUDOS SOBRE EMPREENDEDORISMO E GESTÃO DE PEQUENAS EMPRESAS. 4. 2005, Curitiba, Anais... Curitiba, 2005.

MARCONI, M. A.; LAKATOS, E. M. Técnicas de Pesquisa: planejamento e execução de pesquisas, amostragens e técnicas de pesquisa, elaboração, análise e interpretação de dados. 4 ed. São Paulo: Atlas, 1999.

Fundamentos de metodologia científica. 7 ed. São Paulo: Atlas, 2010.

MCCLELLAND, D. A sociedade competitiva: realização e progresso social. Tradução de Álvaro Cabral. Rio de Janeiro: Expressão e Cultura, 1972.

MELO, A. A educação básica na proposta da Confederação Nacional da Indústria (CNI) nos anos 2000. Educação e Pesquisa, v. 38, n. 1, 2012.

NORTH, D. C. Instituciones, cambio institucional y desempeño econômico. Trad. Agustín Bárcena. México: FCE, 1993.

NUEZ, M. J. A.; GÓRRIZ, C. G. El emprendedor y la empresa: una revision teórica de lós determinantes a su constitución. Acciones e Investigaciones Sociales. Zaragoza, n. 26, 2008.

OLIVEIRA, S. L. Tratado de metodologia científica: projetos de pesquisas, TGI, TCC, monografias, dissertações e teses. 2. ed. São Paulo: Pioneira, 2000.

PALADINO, G. G. Uma questão de gênero. In: GRECO, S. M. S. S. et al. Empreendedorismo no Brasil: 2010. Curitiba: IBQP, 2010. Disponível em: <www.ibqp.org.br/gem>. Acesso em: 25 fev. 2012.

REA, L. M.; PARKER, R. A. Metodologia de Pesquisa: do planejamento à execução. São Paulo: Pioneira, 2000.

RIBEIRO, R. L.; VIEIRA, E. T.; ARAUJO, E. A. S.; OlIVEIRA, E. A. A. Q. Crescimento e desenvolvimento no Litoral Norte Paulista: análise do índice

RIBEIRO, R. L.; ARAUJO, E. A. S.; OLIVEIRA, E. A. A. Q. Mentalidade empreendedora no litoral norte paulista: uma investigação com discentes de ensino superior. Revista de Empreendedorismo e Gestão de Pequenas Empresas, v.4, n.2, 2015 
FIRJAN. In: CONGRESSO DE ADMINISTRAÇÃO, SOCIEDADE E INFORMAÇÃO. 3. 2013, Itatiaia, Anais... Rio de Janeiro, 2013.

SCHLEMM M. M.; PASSOS, C. A. K.; FELIX, J. C.; GRECO, S. M. S. S.; BASTOS JÚNIOR, P. A.; MACHADO, J. P.; KRUPA, S. (Coords). Empreendedorismo no Brasil: 2006. Curitiba: IBQP, 2007. Disponível em: <www.ibqp.org.br/gem>. Acesso em: 25 fev. 2012.

SCHUMPETER, J. A. Teoria do desenvolvimento econômico. Rio de Janeiro: Fundo de Cultura, 1961.

SEADE. Fundação Sistema Estadual de Análise de Dados. Informações dos municípios paulistas. São Paulo: SEADE, 2013. Disponível em: <SPhttp://www.seade.sp.gov.br/produtos/imp/>. Acesso em: 15 dez. 2013.

SEN, A. K. Desenvolvimento como liberdade. São Paulo: Companhia das Letras, 2000.

TIMMONS, J. A.; SPINELLI, S. Criação de novos negócios: empreendedorismo para o século 21. Adaptação da $8^{\mathrm{a}}$ edição americana, José Dornelas. Tradução de Claudia Mello. São Paulo: Elsevier, 2010.

VALE, G. M. V.; WILKINSON, J.; AMÂNCIO R. Empreendedorismo, inovação e redes: uma nova abordagem. Revista de Administração de Empresas Eletrônica, v. 7, n. 1, art. 7, 2008.

VERGARA, S. C. Projetos e relatórios de pesquisa em administração. 6. ed. São Paulo: Atlas, 2005.

RIBEIRO, R. L.; ARAUJO, E. A. S.; OLIVEIRA, E. A. A. Q. Mentalidade empreendedora no litoral norte paulista: uma investigação com discentes de ensino superior. Revista de Empreendedorismo e Gestão de Pequenas Empresas, v.4, n.2, 2015 